\title{
NUMERICAL ANALYSIS OF LIPOQUINONE PATTERNS IN MONITORING BACTERIAL COMMUNITY DYNAMICS IN WASTEWATER TREATMENT SYSTEMS
}

\author{
AKIRA HIRAISHI, ${ }^{*}$ YOSHIAKI MORISHIMA, AND JUN-ICHI TAKEUCHI ${ }^{1}$ \\ Tokyo Research Laboratory, Konishi Co., Ltd., Sumida-ku, Tokyo 130, Japan \\ ${ }^{1}$ Shingashi Treatment Plant, Bureau of Sewage-Works, Tokyo Metropolitan Government, \\ Itabashi-ku, Tokyo 175, Japan
}

(Received September 21, 1990)

\begin{abstract}
The quinone composition of 10 sludge samples consisting of plant-derived activated sludges, laboratory activated sludges, and photosynthetic sludges was analyzed by high-performance liquid chromatography, thin-layer chromatography, and mass spectrometry. The quinone profiles of these sludges showed taxonomic divergence among the sludge bacterial communities. The information could be enhanced by numerical analysis of the profiles using the 'overlap' coefficient and mean linkage algorithm. This analytical system provided quantitative information about the population shift in the indigenous bacterial flora of sludge as affected by physico-chemical or biological stress. The quinone profile method with numerical analysis is quite useful for investigating the bacterial community dynamics over time and space, without the necessity of culturing.
\end{abstract}

Chemotaxonomic approaches to research in microbial ecology are increasingly providing procedures of value for the characterization and identification of bacterial populations in situ(7). Lipoquinone profiling may be one of the most promising methods for this purpose $(6,7)$. This approach involves the determination of isoprenoid quinone contents and structural types as biomarkers of bacterial populations in the environment, whereby the community structure can be characterized without the necessity of culturing. It is now possible to detect environmental quinones easily and rapidly using modern analytical instruments. Structural types of bacterial isoprenoid quinones have been studied extensively for

* Address reprint requests to: Dr. A. Hiraishi, Tokyo Research Laboratory, Konishi Co., Ltd., Yokokawa 5-6-3, Sumida-ku, Tokyo 130, Japan.

Abbreviations used for quinones: $\mathrm{K}_{1}$, phylloquinone; Q- $n$, ubiquinone; MK- $n$, menaquinone; MK- $n\left(\mathrm{H}_{x}\right)$, hydrogenated menaquinone; RQ- $n$, rhodoquinone; $n$ indicates the number of isoprene units and $x$ denotes the number of hydrogen atoms saturating the isoprenoid chain. 
over 20 years, and their taxonomic importance, as well as their functional significance in respiratory and photosynthetic electron transport, has been fully realized $(2,3,18)$. This makes the quinone-profile method very attractive for ecological applications.

Analyses of bacterial communities in biological wastewater treatment systems, represented by activated sludge processes, are of great importance for obtaining fundamental data to provide solutions to practical problems, although researchers in this area for many years have struggled against the problem of how to characterize the communities. But recent chemotaxonomic approaches using the quinones as biomarkers have provided invaluable information about the bacterial population structure in activated sludge systems and some other environments $(4-6,10-12,15)$. In these approaches, differences in the community structure among microbial environments have been noted simply by visual interpretation of profiles. But to enhance the objectivity of the information we need to process data by appropriate statistical analysis. In pure culture studies, numerical analysis of some chemotaxonomic data, such as cellular fatty acid profiles, has been successfully made in grouping bacterial taxa $(l)$. Such a numerical taxonomic technique based on the fatty acid composition has recently been applied to laboratory-scale activated sluged systems (16).

It is the purpose of the present study, therefore, to evaluate the applicability of numerical analysis of lipoquinone profiles to the classification of bacterial communities of various wastewater sludges. We report here the usefulness of this method for monitoring population shifts in the indigenous bacterial flora of wastewater treatment systems.

\section{MATERIALS AND METHODS}

Sludge samples. All sludge samples used are listed in Table 1. Activated sludge was collected from full-scale sewage treatment plants located in Tokyo and Chiba prefectural areas. To prepare laboratory activated sludge, each of the plant-derived sludges was introduced into a $2-l$ glass fermentor and cultivated with synthetic sewage (5) for four weeks. The reactors were operated on a fill-and-draw basis with a $24-\mathrm{h}$ batch cycle as previously described (5). The sludge retention time (SRT) was 7.0 to 9.8 days in all reactors. Photosynthetic sludge was also cultivated with the synthetic sewage in laboratory-scale batch reactors operated on a fill-and-draw basis with a 24 -h batch cycle consisting of a 12-h light stage and a 12-h dark stage as reported previously $(12,13)$. At the start of the operation, the reactors were seeded with one of the laboratory sludges and with cultures of Rhodopseudomonas palustris SA37 and Rhodobacter sphaeroides KA38, both of which were isolated from activated sludge (9). Three types of photosynthetic sludge reactors were made with respect to dissolved oxygen (DO) tension at the light stage: one was kept at a DO level of 2.0 to $3.0 \mathrm{mg} / l$ (type A), the second was at a DO of 0.5 to $1.0 \mathrm{mg} / l$ (type B), and the third was at a DO of 0.3 to $0.5 \mathrm{mg} / l$ (type $\mathrm{C}$ ). In all reactors, the dark stage was aerated at a DO level of 2.0 to $3.0 \mathrm{mg} / \mathrm{l}$. The photosynthetic sludge systems 
showed SRT values of 4.0 to 5.2 days.

Sludge samples were either subjected to quinone analysis immediately after sampling or stored at $-20^{\circ} \mathrm{C}$ pending the extraction.

Quinone extraction and purification. Sludge samples were harvested by centrifugation and washed with $50 \mathrm{~mm}$ potassium phosphate $(\mathrm{pH} 6.8)$ containing $1 \mathrm{~mm}$ ferricyanide. Quinone extraction and purification were performed as described by Hiraishi (5) with some modifications. The sludge pellet $(4-8 \mathrm{~g}$ [wet wt]) was suspended in $1 \%$ saline, mixed with two volumes of chloroform-methanol $(2: 1$, $\mathrm{vol} / \mathrm{vol})$, and then sonicated for $1 \mathrm{~min}$ on ice with an Ohtake disintegrator $(20 \mathrm{kHz}$; output power, $150 \mathrm{~W}$ ), followed by centrifugation at $7,700 \times g$ for $10 \mathrm{~min}$. The resultant upper layer was removed, while the lower lipid layer was saved after filtration. The residue was extracted once with acetone and then twice with the chloroform-methanol mixture ( $1 \mathrm{~h}$ each) with vigorous shaking, and all extracts were filtered, combined, and evaporated under reduced pressure. With the passage of evaporation, the extract became turbid due to the residual water. At this time, it was transferred into a polypropylene centrifuge tube with plag seal cap (Iwaki Glass Co., Ltd., Tokyo, Japan) by eluting with a small amount of acetone and then with hexane. Water was added to the tube to give a hexane/aqueous layer ratio of about $1: 1(\mathrm{vol} / \mathrm{vol})$, which was then agitated for a few minutes to extract the lipid into hexane. This extraction procedure was repeated three times. The extract was concentrated and then applied to column chromatography, for which $8 \mathrm{~g}$ of aluminium oxide 90 active (E. Merck, Darmstadt, FRG) previously washed three times with methanol $(80 \mathrm{ml}$ each) and twice with hexane $(50 \mathrm{ml}$ each) was packed into a glass column $(1.5 \times 30 \mathrm{~cm})$ and equilibrated with hexane. The hexane-extracted sample was applied to the top of the column and eluted with $70 \mathrm{ml}$ of hexane-diethyl ether $(90: 10, \mathrm{vol} / \mathrm{vol})$. The eluted fraction was concentrated, dissolved in a small amount of acetone, and then subjected to thin-layer chromatography (TLC) to purify the quinones. Quantitative TLC was performed with Kieselgel $60 \mathrm{~F}_{254}$ precoated plates (Merck) and a developing mixture of hexane-diethyl ether (85: 15, $\mathrm{vol} / \mathrm{vol})$.

Spectrophotometry. Purified quinones were examined spectrophotometrically to verify their purity and to determine concentrations. Quinone concentrations were determined by the difference spectrum $\left(\mathrm{KBH}_{4}\right.$-reduced vs. oxidized), using the following difference extinction coefficients: ubiquinone, $\Delta \varepsilon=-8.8 \mathrm{~mm}^{-1} \cdot \mathrm{cm}^{-1}$ at 280-289 $\mathrm{nm}$ (14); menaquinone, $\Delta \varepsilon=22.7 \mathrm{~mm}^{-1} \cdot \mathrm{cm}^{-1}$ at $248-253.6 \mathrm{~nm}$ (14); rhodoquinone, $\Delta \varepsilon=-7.9 \mathrm{~mm}^{-1} \cdot \mathrm{cm}^{-1}$ at $283 \mathrm{~nm}(8)$.

High-performance liquid chromatography (HPLC) The quinone components were separated by reverse-phase HPLC with a Shimadzu liquid chromatograph equipped with a Zorbax ODS column and a mobile phase of methanol-isopropyl ether $(3: 1, \mathrm{vol} / \mathrm{vol})$ as described previously $(5,17)$. To purify quinone components to be subjected to further analysis, a methanol-isopropanol mixture $(1: 1, \mathrm{vol} / \mathrm{vol})$ was used as the eluent. Separated quinones were identified by comparing their elution times with those of standard quinones. The concentration of each quinone 
component was calculated by multiplying the percentage of the total HPLC peak area recorded for it by the total concentration that had been spectrophotometrically measured.

Argentation-modified TLC. This was performed to obtain information on the hydrogenation of the side chain of quinones. Although $\mathrm{Ag}^{+}$-impregnated TLC plates are usually used for this purpose (2), we used an $\mathrm{Ag}^{+}$-containing developing solvent alternatively. HPLC-separated quinones were spotted onto LKC18F reverse-phase precoated plates (Whatman K.K., Tokyo, Japan) and developed in a mixture of acetone- $50 \% \mathrm{AgNO}_{3}(90: 10, \mathrm{vol} / \mathrm{vol})$. The chromatograms were visualized by spraying a $10 \%$ ethanolic solution of molybdophosphoric acid and heating at $120^{\circ} \mathrm{C}$ for a few minutes. This system allowed separation of quinones according to the degree of saturation of their side chain, independent of the number of isoprene units, and thus, the number of double bonds they contain could be determined easily by comparing their mobility to that of authentic hydrogenated quinones.

Mass spectrometry. This was performed with a JEOL DX300 mass spectrometer at an ionization voltage of $70 \mathrm{eV}$. The relative proportions of isoprenologs in a mixture which HPLC separated poorly were determined by comparing the intensity of peaks corresponding to their molecular ions $\left(\mathrm{M}^{+}\right)$.

Standard quinones. Phylloquinone, Q-6, and Q-7 were obtained from Sigma Chemical Co. (St. Louis, USA). Higher ubiquinone isoprenologs (Q-8 to Q-10), menaquinones (MK-7 to MK-12), and rhodoquinones (RQ-8 to RQ-10) were prepared from authentic strains of some species of phototrophic purple bacteria (8) and Aureobacterium testaceum IAM 1561. Partially saturated menaquinones were from Micrococcus luteus IAM 12144, Arthrobacter globiformis IAM 12102 and Streptomyces albus JCM 4177.

Numerical analysis. The concentration of quinone components detected in one sample were expressed as percentages of the total quinone content. After the values of less than $0.1 \%$ and for unidentified components were excluded, the percentages were recalculated to give the total of 100, and this set of data was used for numerical analysis. Similarities or dissimilarities were calculated initially by two different measures based on the correlation coefficient and overlap of percentages according to Bousfield et al.(1). These measures gave essentially the same results in cluster analysis. Therefore, only the data obtained from the measure based on the 'overlap' coefficient are reported in this paper. The reason for this selection was that the calculation of similarity or dissimilarity values by the overlap method is simpler, and this measure is more effective in emphasizing differences in profiles among samples. In this study, we stressed dissimilarity rather than similarity, and thus defined the dissimilarity index $(D)$ as follows:

$$
D(i, j)=1 / 2 \sum_{k=1}^{P}\left|x_{i k}-x_{j k}\right|,
$$

where 


$$
\sum x_{i k}=\sum x_{j k}=100
$$

and $x_{i k}$ and $x_{j k}$ are the precentages of the $k$ quinone component for the $i$ and $j$ samples, respectively.

When assessing population shifts in the bacterial flora with time in a wastewater treatment unit, the dissimilarity index could also be defined as follows:

$$
D(0, t)=1 / 2 \sum_{k=1}^{P}\left|x_{o k}-x_{t k}\right|,
$$

where $x_{o k}, x_{t k}$ are the percentage of the $k$ quinone component for the initial and the $t$-day-incubated sample, respectively.

When determining population changes in quinone-categorized individual taxa in a sludge system, the overlap of percentages for individual quinone homologs $\left(D_{k}\right)$ could be used:

$$
D_{k}(0, t)=-\left(x_{o k}-x_{t k}\right),
$$

where $x_{o k}$ and $x_{t k}$ are as defined above.

Thus, positive and negative $D_{k}$ values would mean, respectively, an increase and a decrease in the proportion of populations with the $k$ quinone system after $t$ days of operation.

Calculating the dissimilarity values and clustering (by the group average linkage method) were achieved using an NEC PC9801 personal computer and programs written by one of us (A.H.).

\section{RESULTS AND DISCUSSION}

\section{Quinone profiles of sludges from different sources}

The distribution of isoprenoid quinones in 10 sludge samples from different sources was investigated. Information on the sources and quinone contents of these sludges is given in Table 1. The tested samples consisted of four activated sludges from sewage treatment plants, three activated sludges from laboratory reactors seeded with the plant-derived sludges, and three photosynthetic sludges from laboratory reactors operated under different conditions. Almost equal amounts of ubiquinones and menaquinones were detected in all activated sludges from the plants (sample Nos. 1-4), while the former group of quinones occurred in much higher amounts than the latter in all laboratory sludges (sample Nos. 5-10). In particular, the photosynthetic sludges (sample Nos. 8-10) were characterized by the occurrence of high concentrations of ubiquinones, as already reported elsewhere(12). In some sludges, much smaller but detectable amounts of rhodoquinones were found in addition.

The lipoquinone patterns of the 10 sludges are shown in Table 2, where the data are expressed as percentages of the total quinone contents (ubiquinones + menaquinones + rhodoquinones). Previous reports have shown that in activated sludge 
Table 1. List of wastewater sludges studied and their quinone contents

\begin{tabular}{|c|c|c|c|c|c|}
\hline \multirow{2}{*}{$\begin{array}{l}\text { Sample } \\
\text { No. }\end{array}$} & \multirow{2}{*}{$\begin{array}{l}\text { Type of sludge } \\
\text { and wastewater }\end{array}$} & \multirow{2}{*}{ Source } & \multicolumn{3}{|c|}{$\begin{array}{l}\text { Quinone content } \\
(\mu \mathrm{mol} / \mathrm{g} \text { dry } w \mathrm{t})\end{array}$} \\
\hline & & & Q & MK & RQ \\
\hline & \multicolumn{5}{|l|}{ Plant activated sludge } \\
\hline 1 & Municipal sewage & Plant A, Tokyo & 0.504 & 0.496 & - \\
\hline 2 & Municipal sewage & Plant B, Tokyo & 0.449 & 0.452 & - \\
\hline 3 & Municipal sewage & Plant C, Tokyo & 0.585 & 0.528 & - \\
\hline 4 & Municipal sewage & Plant D, Chiba & 0.401 & 0.387 & - \\
\hline \multicolumn{6}{|c|}{ Laboratory activated sludge } \\
\hline 5 & Synthetic sewage & $\begin{array}{l}\text { This laboratory, } \\
\text { seed sludge from plant A }\end{array}$ & 0.623 & 0.312 & - \\
\hline 6 & Synthetic sewage & $\begin{array}{l}\text { This laboratory, } \\
\text { seed sludge from plant B }\end{array}$ & 0.540 & 0.356 & 0.009 \\
\hline 7 & Synthetic sewage & $\begin{array}{l}\text { This laboratory, } \\
\text { seed sludge from plant D }\end{array}$ & 0.656 & 0.326 & 0.005 \\
\hline \multicolumn{6}{|c|}{ Photosynthetic sludge $^{a}$} \\
\hline 8 & Type A, synthetic sewage & This laboratory & 1.190 & 0.192 & - \\
\hline 9 & Type B, synthetic sewage & This laboratory & 1.220 & 0.301 & - \\
\hline 10 & Type C, synthetic sewage & This laboratory & 1.350 & 0.370 & 0.017 \\
\hline
\end{tabular}

a For cultivating photosynthetic sludge, activated sludge from a laboratory reactor (sample No. 6) was used as the seed. Sludges designated type A, B, and C were cultivated under different DO conditions at the light stage (see MATERIALS AND METHODS).

systems, Q-8 occurs as the commonest ubiquinone, Q-10 is the second most common, and Q-9 and other ubiquinones are present as minor components $(5,10,11)$. This was confirmed by the present study. On the other hand, Q-10 occurred in higher proportions in the photosynthetic sludges. In particular, this was the case in the sludges cultured under DO-limited conditions (sample Nos. 9 and 10), probably due to the occurrence of high numbers of phototrophic bacteria containing Q-10 as the major quinone. Concurrent studies in our laboratory have shown that the phototrophic bacteria with Q-10 constituted a high proportion of the bacterial flora of photosynthetic sludge in a full-scale plant(12). Menaquinone profiles were complicated in the activated sludges but were quite simple in the photosynthetic sludges. In the former sludges either $\mathrm{MK}-7, \mathrm{MK}-8$, or $\mathrm{MK}-8\left(\mathrm{H}_{4}\right)$ predominated, whereas MK- $9\left(\mathrm{H}_{4}\right)$ was the major type in the latter.

In this study, we found that the HPLC system used gave poor separation of MK-8 $\left(\mathrm{H}_{4}\right)$ and MK-9 or MK-9 $\left(\mathrm{H}_{4}\right)$ and MK-10 from each other. Therefore, we had to perform $\mathrm{Ag}^{+}$-modified TLC and mass spectrometry to identify these quinone types. Although MK-9 and MK-10 were previously reported to occur in significant proportions in some sludges $(5,10,12)$, the present study showed that these menaquinones were present only as minor components in all tested sludges. Therefore, the previous data may result partly from misidentification. Since tetrahydrogenated menaquinones with eight or nine isoprene units occur frequently 
Table 2. Quinone composition of activated sludge and photosynthetic sludge samples from different sources. ${ }^{a}$

\begin{tabular}{|c|c|c|c|c|c|c|c|c|c|c|c|}
\hline \multirow{2}{*}{$\begin{array}{l}\text { Quinone } \\
\text { type }\end{array}$} & \multicolumn{11}{|c|}{ Composition (mol\%) } \\
\hline & Sample No. & 1 & 2 & 3 & 4 & 5 & 6 & 7 & 8 & 9 & 10 \\
\hline Q-5 & & 0.3 & 0.1 & 0.2 & 0.1 & - & - & - & - & - & - \\
\hline Q-6 & & 0.2 & 0.4 & 0.7 & 0.8 & 0.1 & 0.2 & 0.1 & - & - & - \\
\hline Q-7 & & 0.9 & 0.4 & 1.3 & 0.8 & 0.7 & 0.7 & 1.5 & 4.0 & 5.0 & 6.7 \\
\hline Q-8 & & 34.3 & 34.6 & 36.7 & 33.8 & 42.8 & 45.5 & 47.3 & 60.3 & 41.9 & 21.3 \\
\hline Q-9 & & 4.4 & 3.3 & 4.0 & 3.9 & 1.9 & 1.7 & 2.0 & 2.0 & 2.6 & 3.7 \\
\hline Q-10 & & 9.5 & 11.0 & 9.4 & 11.9 & 21.4 & 11.4 & 15.4 & 20.3 & 30.7 & 46.4 \\
\hline $\mathrm{K}_{1}$ & & - & - & 0.3 & - & 0.3 & 0.1 & 0.3 & - & - & - \\
\hline MK-5 & & - & 0.2 & 0.6 & 0.3 & 0.5 & 0.3 & 0.3 & - & 0.2 & 0.4 \\
\hline MK-6 & & 1.8 & 2.3 & 5.2 & 5.4 & 1.3 & 2.5 & 2.1 & 0.1 & 1.3 & 2.5 \\
\hline MK-7 & & 7.4 & 7.5 & 9.2 & 7.9 & 7.4 & 12.0 & 13.2 & 2.3 & 3.7 & 3.8 \\
\hline MK-8 & & 10.9 & 9.7 & 9.0 & 5.1 & 6.5 & 4.3 & 4.4 & 0.7 & 0.7 & 0.4 \\
\hline MK-9 & & 0.5 & 0.5 & 0.5 & 0.5 & 1.0 & 1.0 & 0.3 & 0.1 & - & 0.1 \\
\hline MK-10 & & 0.9 & 1.4 & 0.9 & 1.3 & 1.0 & 0.4 & 0.6 & - & - & - \\
\hline MK-11 & & 0.3 & 0.4 & 0.4 & 0.3 & 0.2 & 0.6 & 0.5 & - & - & - \\
\hline MK-12 & & 0.2 & 0.3 & 0.3 & 0.1 & - & - & 0.1 & - & - & - \\
\hline $\mathrm{MK}-7\left(\mathrm{H}_{2}\right)$ & & 1.8 & 1.4 & 1.0 & - & 0.4 & 0.8 & 0.4 & - & - & - \\
\hline $\mathrm{MK}-8\left(\mathrm{H}_{2}\right)$ & & 3.5 & 4.1 & 2.9 & 6.9 & 1.4 & 1.0 & 0.7 & - & - & - \\
\hline MK- $8\left(\mathrm{H}_{4}\right)$ & & 10.2 & 12.2 & 9.1 & 7.3 & 10.4 & 14.1 & 8.3 & 1.3 & 1.8 & 0.3 \\
\hline MK-9( $\left.\mathrm{H}_{2}\right)$ & & 6.3 & 5.2 & 3.1 & 4.4 & 0.6 & 0.5 & 0.3 & - & - & - \\
\hline MK-9( $\left.\mathrm{H}_{4}\right)$ & & 2.1 & 2.2 & 2.5 & 1.7 & 1.6 & 1.1 & 1.4 & 8.7 & 12.0 & 13.2 \\
\hline MK-9 $\left(\mathrm{H}_{6}\right)$ & & 0.1 & - & - & 0.1 & - & - & - & - & - & - \\
\hline MK-9( $\left.\mathrm{H}_{8}\right)$ & & 3.0 & 2.4 & 2.3 & 7.5 & 0.7 & 0.3 & 0.1 & - & - & - \\
\hline $\mathrm{MK}-10\left(\mathrm{H}_{2}\right)$ & & 0.1 & - & - & - & - & - & - & - & - & - \\
\hline RQ-8 & & - & - & - & - & - & 1.0 & 0.2 & - & - & 0.3 \\
\hline RQ-10 & & - & - & - & - & - & - & - & - & - & 0.7 \\
\hline
\end{tabular}

a For information on sludge sources, see Table 1.

as major menaquinones in wastewater sludge, as reported here and elsewhere (12), close attention should be paid to the identification of these menaquinones, for which reverse-phase HPLC by itself is insufficient and it is necessary to use $\mathrm{Ag}^{+}$-modified chromatography and/or mass spectrometry in addition.

Numerical analysis for clustering

The dissimilarity values for the 10 sludge samples were obtained from each of the ubiquinone, menaquinone, and total quinone profiles. Thus, three dendrograms for clustering the sludges were obtained using the average linkage algorithm with the overlap coefficient (Fig. 1). Clustering based on the ubiquinone profiles revealed that the municipal sewage sludges formed a cluster at a dissimilarity level of less than $10 \%$, whereas the laboratory activated sludges and photosynthetic sludges crossed each other at higher dissimilarity levels (Fig. 1A). In clustering based on the menaquinone profiles, the sludges were divided into three groups at the $25 \%$ 


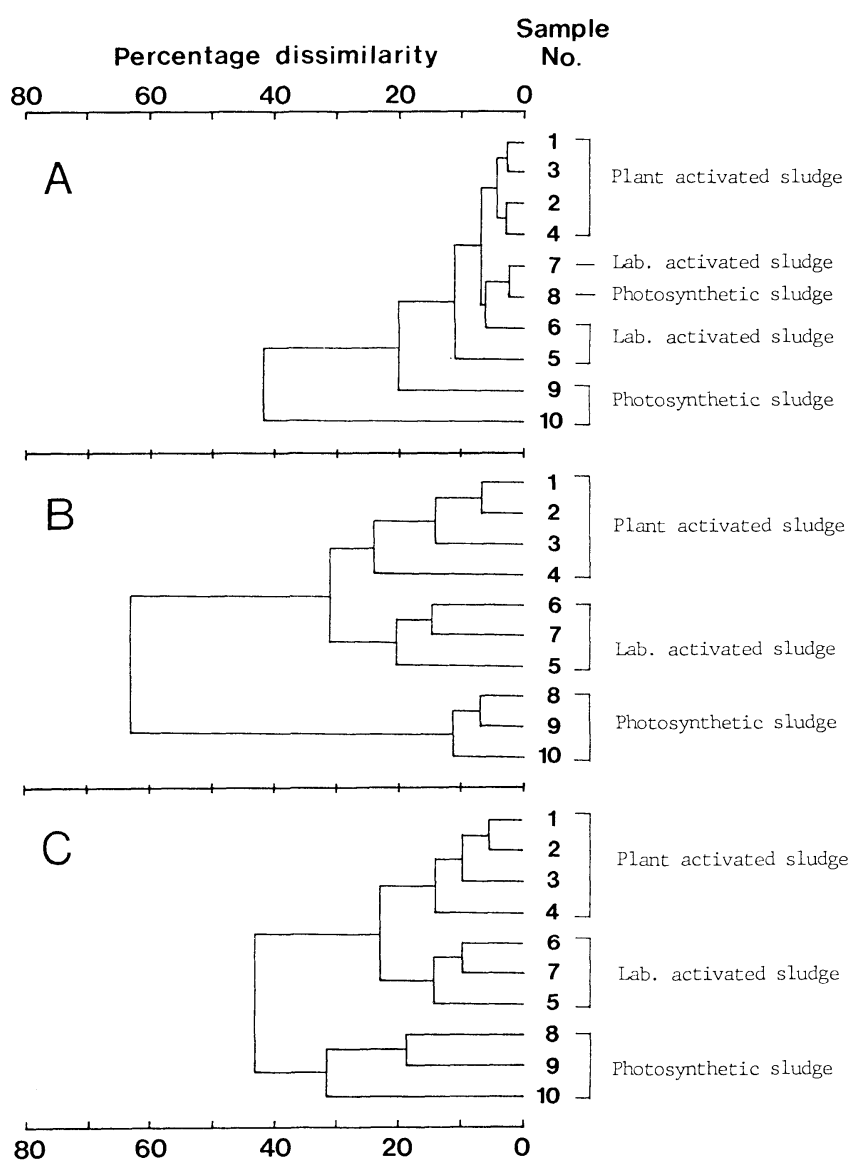

Fig. 1. Clustering of wastewater sludges with the overlap coefficient and average linkage algorithm based on ubiquinone (A), menaquinone (B), and total quinone (C) profiles.

level: the first group consisted of all municipal sewage sludges, the second included all laboratory activated sludges, and the third was made up of all photosynthetic sludges (Fig. 1B). Two major clusters, the former two groups vs. the latter one, were also recorded at the $60 \%$ level. Similar results were obtained with clustering based on the total quinone composition (Fig. 1C). In this clustering, the sludges were classified into the following four groups at a dissimilarity level of $20 \%$ : the municipal sewage sludge group, the laboratory activated sludge group, and two photosynthetic sludge groups. Also, two major clusters which consisted of all activated sludges and all photosynthetic sludges, respectively, were obtained at the $40 \%$ level.

As described above, the cluster analysis with the overlap coefficient and average linkage argorithm based on the quinone composition provided the quantitative 
information about differences in the community structure among the wastewater sludges from a variety of places and reactors. The sludges from three different operational sources, i.e., those from municipal sewage treatment plants, those from laboratory activated sludge reactors, and those from photosynthetic sludge systems, could be separated from each other on the basis of the total quinone composition. This indicates that there was more similarity in the bacterial community structure among the sludges within one of the three groups than between the laboratory sludges and their seed sludges. It is therefore clear that population shifts in the indigenous bacterial flora from the seed sludges to the laboratory sludges took place in response to different operational conditions (e.g., chemical composition of wastewater, wastewater-loading rates, scale of reactors). Activated sludge cultured in a well-controlled reactor showed a narrow range of the dissimilarity of less than $10 \%$ (data not shown). In view of this and the dissimilarity level at which the laboratory sludges and the municipal sewage sludges could be separated from each other (Fig. 1C), it is suggested that a $D$ level between 10 and $20 \%$ can be used as a criterion for classifying bacterial communities of wastewater sludges.

The results presented in Fig. 1 show that the menaquinone composition gave a dendrogram more similar to that based on the total quinone profile than did the ubiquinone composition. The reason for this is that many more menaquinone homologs were detected and compared than ubiquinone homologs, so the total quinone composition depended largely upon the former group of quinones. Therefore, the menaquinone profile may be used independently for classifying bacterial populations in wastewater sludges.

\section{Changes in bacterial communities during acclimation}

The cluster analysis of the sludges based on lipoquinone profiles (Fig. 1) has demonstrated that population shifts in the indigenous bacterial flora occurred from the seed sludges to the laboratory sludges after four weeks of cultivation with synthetic sewage. As an example, the time course of changes in the profiles of one of the synthetic sewage-fed laboratory sludges during the acclimation is shown in Fig. 2. The dissimilarity value sharply increased during the first two weeks, but remained constant thereafter.

In that case, the reactor was operated at an SRT between 7.1 and 8.2 days, an average of 7.4 days, during the whole course of the experiment. Therefore, it is suggested that it takes twice the SRT time to complete the acclimation, as judged by quinone profiling.

\section{Population shifts from activated sludge to photosynthetic sludge}

We also used the quinone profile method with numerical analysis to monitor specific exogenous bacteria introduced into activated sludge and to assess their effects on the sludge bacterial flora under different operational conditions. The phototrophic bacteria containing Q-10, Rhodopseudomonas palustris and Rhodobacter sphaeroides, were selected for this purpose. In activated sludge, the 


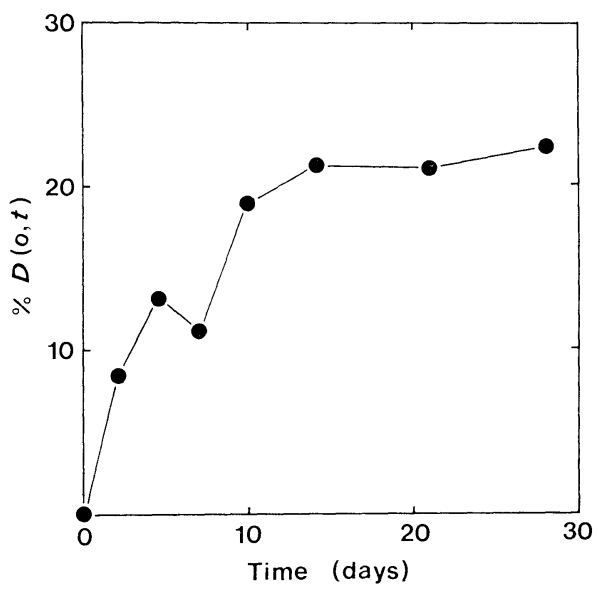

Fig. 2. Change of $D(0, t)$ values for activated sludge during the period of acclimation to synthetic sewage. A laboratory reactor was seeded with municipal sewage sludge from plant A and operated with feeding synthetic sewage at an SRT of 7.1 to 8.2 days. The quinone composition of sludge sampled at appropriate intervals of operation was analyzed, and the dissimilarity between the seed sludge and each of the sampled sludges was determined.

phototrophic bacteria occur only in negligible numbers compared to co-existent aerobic heterotrophs (9), but can compete with them, provided that the sludge is acclimated to high-strength organic nutrients under aerobic-light conditions (i.e., the conditions favorable for photosynthetic sludge)(13). Thus, we added the phototrophic bacteria into activated sludge reactors, and then monitored their fate and the total community dynamics when operating the reactors under both conditions used for the activated sludge process and the photosynthetic sludge system.

The time courses of the variation of the community in the two reactors after the addition of the phototrophs are shown in Fig. 3. In this experiment, the $D_{k}(0, t)$ value for $\mathrm{Q}-10\left(D_{\mathrm{Q} 10}\right)$ and the $D(0, t)$ value were used to assess the phototrophic bacterial populations and the total community dynamics, respectively. In both reactors, $D_{\mathrm{Q} 10}$ increased up to $23 \%$ just after the addition of the phototrophic bacteria, as naturally expected. In the photosynthetic sludge reactor (Fig. 3A), the $D_{\mathrm{Q} 10}$ value rapidly declined during the first 2 days but reached a steady-state between 13 and $16 \%$ afterward. The change in the $D$ level was almost the same as that in $D_{\mathrm{Q} 10}$ during the first 4 days. However, the $D$ value rapidly increased after 7 days of operation and reached twice the level of $D_{\mathrm{Q} 10}$ at the end of the experiment. In the activated sludge reactor (Fig. $3 \mathrm{~B}$ ), on the other hand, both $D_{\mathrm{Q} 10}$ and $D$ rapidly declined from $23 \%$ to the similar levels found before adding the phototrophs during the first 7 days.

The above experimental results show great differences in the population 


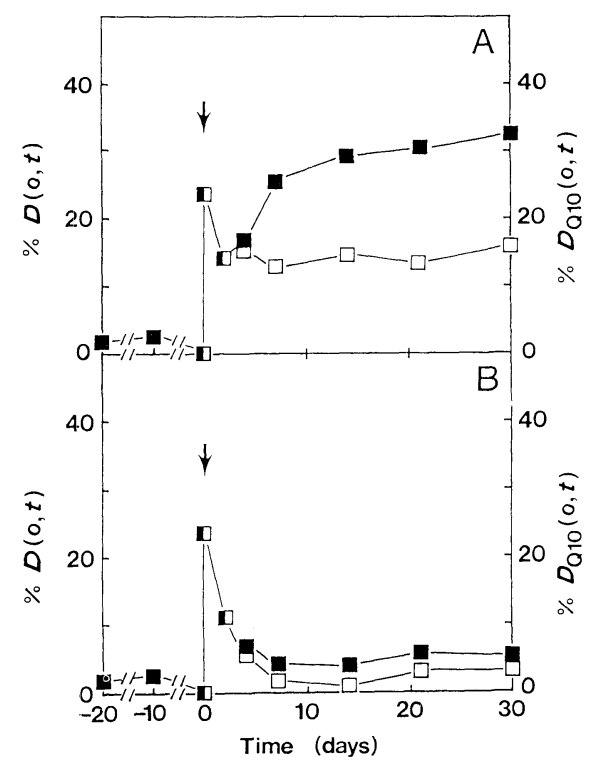

Fig. 3. Changes of $D(0, t)$ and $D_{\mathrm{Q} 10}(0, t)$ values for phototroph-incorporated sludges during the period of cultivation under conditions for photosynthetic sludge (A) and activated sludge (B). Symbols: - - $D(0, t) ;-\square-, D_{\mathrm{Q} 10}(0, t)$. Activated sludge in a laboratory reactor which had been cultivated for 20 days was divided into two equal portions, to which washed cell suspensions of Rhodopseudomonas palustris SA37 and Rhodobacter sphaeroides KA38 previously grown in MYC medium(9) under microaerobic-light conditions were added to give viable counts of $8.2 \times 10^{8} / \mathrm{ml}$ (at points indicated by arrows). The phototroph-incorporated sludges were then cultivated with synthetic sewage as either photosynthetic sludge (DO condition, type B) or activated sludge. The quinone composition of sludges sampled at appropriate intervals of operation was analyzed, and the dissimilarities between the sludge just before the phototrophs were added and each of the sampled sludges were determined. $D_{\mathrm{Q} 10}$ values obtained before the addition were not plotted.

dynamics after introducing the phototrophic bacteria between the reactors operated as the photosynthetic sludge system and as the activated sludge system. The photosynthetic sludge reactor was operated under the conditions favorable for the growth of anoxygenic phototrophs, so that the added bacteria could keep occurring in high numbers during the period of operation, as suggested by the increased level of $D_{\mathrm{Q} 10}$. However, the greater increase in the $D$ value found in the photo-reactor indicates that the population shifts from the activated sludge to the photosynthetic sludge resulted not only from the proliferation of the phototrophic bacteria but also from that of some other bacteria which were not major constituents of the normal flora of the former sludge (see detailed discussion below). In contrast, the fact that the $D$ level rapidly decreased with time in parallel with $D_{\mathrm{Q} 10}$ in the activated sludge reactor shows that this reactor allowed neither the growth of the phototrophic bacteria nor major changes in the bacterial flora. 


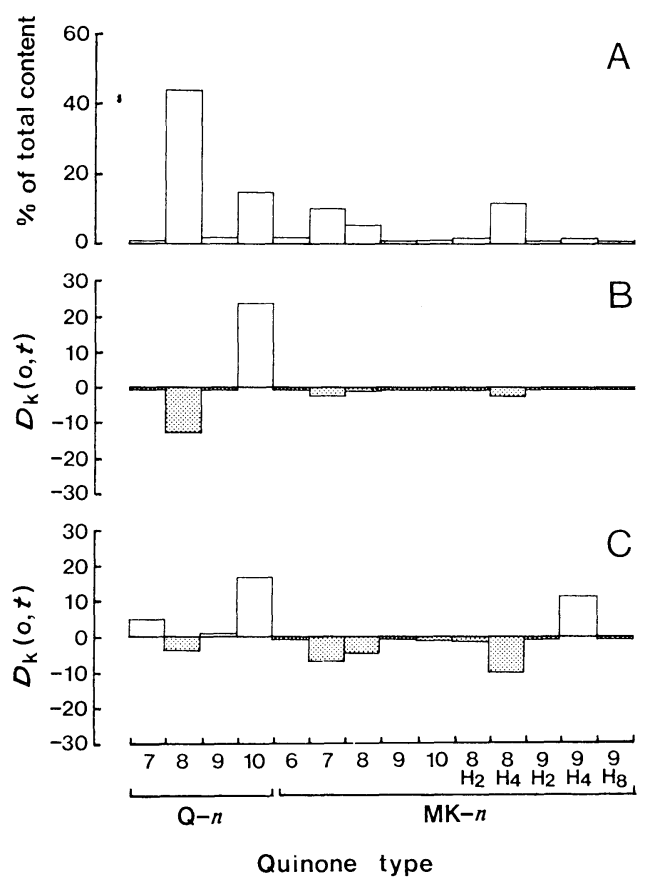

Fig. 4. Population shifts in the bacterial flora from laboratory activated sludge to photosynthetic sludge, as determined by quinone profiling. A, quinone profiles of activated sludge just before the phototrophs were added; $\mathrm{B}, D_{k}$ profiles of the sludges just before and after the addition; $\mathrm{C}, D_{k}$ profiles of the sludges just before the addition and at the end of operation (after 30 days). For experimental conditions, see Fig. 3 legend.

Figure 4 shows which bacteria contributed to the population shifts from the activated sludge to the photosynthetic sludge during the acclimation. Naturally, only $D_{\mathrm{Q} 10}$ was positive just after the addition of the phototrophic bacteria with Q-10 (Fig. 4B). At the end of operation, however, positive $D_{k}$ values were found for Q-7 and MK-9 $\left(\mathrm{H}_{4}\right)$ in addition, and the $D_{k}$ for MK-7, MK-8, and MK-8 $\left(\mathrm{H}_{4}\right)$ also decreased more compared with those at the start of operation (Fig. 4C). These observations show that the change in the community structure was caused mainly by the proliferation of the added phototrophic bacteria, the increasing levels of bacteria containing Q-7 or MK-9 $\left(\mathrm{H}_{4}\right)$ which were not major constituents of the normal flora of the activated sludge (Fig. 4A), and the decline in bacteria with MK-7, MK-8, and MK-8( $\left.\mathrm{H}_{4}\right)$.

To advance research in microbial ecology, we need to develop reliable techniques for assessing the ecological effects of physico-chemical or biological stress on bacterial communities in situ. This is becoming increasingly important with increasing interest in the ecology of genetically engineered microorganisms intentionally or accidentally released into the environment and their impact on 
ecosystems. Research on this subject has focused mainly on monitoring a specific microorganism under controlled conditions, and little attention has been paid to changes in the total community structure. In this respect, lipoquinone profiling with numerical analysis may provide criteria of promise in assessing the ecological effects of exogenous bacteria, as well as of physico-chemical stress, on the indigenous flora of wastewater treatment systems and other environments.

In summary, the results of this study extend the previous reports on the quinone profiles of wastewater sludges $(5,10-12)$ and provide evidence that the numerical analysis of lipoquinone patterns with the overlap coefficient can enhance the information about bacterial community dynamics in these ecosystems. Thus, the strength of the quinone profile method lies not only in that the taxonomic structure of bacterial communities can be assessed by comparing their quinone profiles to the chemotaxonomic data on known bacterial taxa but also in that the variation of the bacterial population structure over space and time can be quantified and objectified by numerical analysis of the profiles. This is a simple but novel method that avoids the need of culturing and mediates between autoecological and synecological approaches. Further studies are currently under way to combine this method with molecular genetic techniques for in situ analysis of bacterial populations in various environments.

\section{REFERENCES}

1) Bousfield, I. J., Smith, G. L., Dando, T. R., and Hobbs, G., Numerical analysis of total fatty acid profiles in the identification of coryneform, nocardioform and some other bacteria. J. Gen. Microbiol., 129, 375-394 (1983).

2) Collins, M. D., Analysis of isoprenoid quinones. In Methods in Microbiology, Vol. 18, ed. by Gottschalk, G., Academic Press, London (1985), p. 329-366.

3) Collins, M. D. and Jones, D., Distribution of isoprenoid quinone structural types and their taxonomic implications. Microbiol., Rev., 45, 316-354 (1981).

4) Hedrick, D. B. and White, D. C., Microbial respiratory quinones in the environment. I. A sensitive liquid chromatographic method. J. Microbiol. Methods, 5, 243-254 (1986).

5) Hiraishi, A., Respiratory quinone profiles as tools for identifying different bacterial populations in activated sludge. J. Gen. Appl. Microbiol., 34, 39-56 (1988).

6) Hiraishi, A., Isoprenoid quinone profiles for identifying and classifying microorganisms in the environment. In Recent Advances in Microbioal Ecology, ed. by Hattori, T., Ishida, Y., Maruyama, Y., Morita, R. Y., and Uchida, A., Japan Scientific Societies Press, Tokyo (1989), p. 663-668.

7) Hiraishi, A., Application of chemotaxonomic and molecular genetic methods for in situ identification of microbial populations in the environment. Proc. Adv. Mar. Tech. Conf., 3, 21-28 (1990).

8) Hiraishi, A. and Hoshino, Y., Distribution of rhodoquinone in Rhodospirillaceae and its taxonomic implications. J. Gen. Appl. Microbiol., 30, 435-448 (1984).

9) Hiraishi, A. and Kitamura, H., Distribution of phototrophic purple nonsulfur bacteria in activated sludge systems and other aquatic environments. Bull. Jpn. Soc. Sci. Fish., 50, 1929-1937 (1984).

10) Hiraishi, A., Masamune, K., and Kitamura, H., Characterization of the bacterial population structure in an anaerobic-aerobic activated sludge system on the basis of respiratory quinone profiles. Appl. Environ. Microbiol., 55, 897-901 (1989).

11) Hiraishi, A. and Morishima, Y., Capacity for polyphosphate accumulation of predominant bacteria 
in activated sludge showing enhanced phosphate removal. J. Ferment. Bioeng., 69, 368-371 (1990).

12) Hiraishi, A., Morishima, Y., and Kitamura, H., Use of isoprenoid quinone profiles to study the bacterial community structure and population dynamics in the photosynthetic sludge system. Water Sci. Technol., 23, 937-945 (1991).

13) Hiraishi, A., Shi, J.-L., and Kitamura, H., Effects of organic nutrient strength on the purple nonsulfur bacterial content and metabolic activity of photosynthetic sludge for wastewater treatment. J. Ferment. Bioeng., 68, 267-276 (1989).

14) Kröger, A., Determination of contents and redox states of ubiquinone and menaquinone. Methods Enzymol., 53, 579-591 (1978).

15) Kuraishi, H., Kagakubunruigaku-teki giho ni yoru kasseiodei biseibutsuso no ruibetsuka (Classification of the bacterial flora of activated sludge by chemotaxonomic methods) (in Japanese). Biseibutsu no seitai 13, ed. by the Japanese Society for Microbial Ecology, Japan Scientific Societies Press, Tokyo (1985), p. 125-138.

16) Suwa, Y., Urushigawa, Y., Matsui, Y., and Yamaguchi, F., Shibousan sosei bunseki ni yoru kasseiodei biseibutsuso no hendo kenshutsuho no kento (Changes in fatty acid composition of activated sludges acclimated with starch and butyrate) (in Japanese). Kogai, 25, 137-144 (1990).

17) Tamaoka, J., Katayama-Fujimura, Y., and Kuraishi, H., Analysis of bacterial menaquinone mixtures by high performance liquid chromatography. J. Appl. Bacteriol., 54, 31-36 (1983).

18) Yamada, Y., Kokyusa ni kanyosuru kinonrui no bunshishu ni motozuku biseibutsu no bunrui (Classification of microorganisms on the basis of respiratory quinone systems) (in Japanese). Hokko to Kyogyo, 37, 940-954 (1979). 